Çukurova Üniversitesi Mühendislik Mimarlık Fakültesi Dergisi, 32(1), ss. 223-233, Mart 2017

Çukurova University Journal of the Faculty of Engineering and Architecture, 32(1), pp.223-233, March 2017

\title{
Karbon Lifi/Epoksi Tabakalı Kompozit Malzemelerin Farklı Ortam Şartlarındaki Mod I Kırılma Davranışı
}

\author{
Fatih DARICIK ${ }^{1}$, Kerimcan ÇELEBI' ${ }^{* 1}$ \\ ${ }^{1}$ Adana BTU, Mühendislik ve Doğa Bilimleri Fakültesi, Makine Mühendisliği Bölümü, Adana
}

Geliş tarihi: 26.02.2017 Kabul tarihi: 14.03.2017

$\ddot{O} z$

Tabakalar arası çatlak ve kırılma, tabakalı kompozit malzemelerde çokça karşılaşılan bir hasar türüdür. Ayrılma modu tabakalar arası kırılmanın en kolay gerçekleştiği ve tabakalar arası kırılma tokluğunun en düşük olduğu kırılma modudur. Bu çalışmada $140^{\circ} \mathrm{C}$ ile $-160^{\circ} \mathrm{C}$ aralığındaki ortam sıcaklıklarının karbon lifi/epoksi kompozit malzemenin Mod I tabakalar arası kırılma tokluğuna ve kırılma mekaniğine etkisi araştırılmıştır. Elde edilen bulgularda ortam sıcaklığı $0^{\circ} \mathrm{C}^{\prime}$ nin altına düştüğünde tabakalar arası kırılma tokluğu, $23^{\circ} \mathrm{C}$ ortam sıcaklığındaki kırılma tokluğuna göre azalmıştır. Ancak düşük ortam sıcaklıklarındaki kırılma karakteristiği $23^{\circ} \mathrm{C}$ sıcaklıktaki kırılma karakteristiğine benzerdir. Yüksek ortam sıcaklıklarında ise matris malzemenin camsı geçiş sıcaklığı çatlak gelişimi için doğal bir limit oluşturmaktadır. Epoksi matrisin camsı geçiş sıcaklığına yakın sıcaklıklarda çatlak ilerlememiştir. Camsı geçiş sıcaklığının üzerindeki sıcaklıklarda ise malzemenin kırılma davranışı tamamen değişmiştir.

Anahtar Kelimeler: Karbon/epoksi, Mod I, Tabakalar arası kırılma, Sıcaklık etkisi

\section{Mode I Interlaminar Fracture Behaviour of Carbon/Epoxy Laminated Composites under Different Temperatures}

\begin{abstract}
Interlaminar fracture of a laminated composite material is the damage resistance of the material to cracks located at interface. Mode I interlaminar fracture takes place and damages composites more easily than other modes since it is frictionless. In this study, the effect of ambient temperature to mod I interlaminar fracture toughness of carbon/epoxy laminate was studied. It is found out that if the ambient temperature decreases under $0^{\circ} \mathrm{C}$, Mod I interlaminar fracture toughness decreases also. However fracture behavior doesn't change and R-curve behaviors of laminates are similar under the $23^{\circ} \mathrm{C}$ and below. For higher ambient temperatures than $23^{\circ} \mathrm{C}$, it is concluded that glass transition temperature $\left(T_{g}\right)$ of epoxy matrix is key parameter and the crack doesn't propagate if the temperature is close to $T_{g}$. Fracture characteristics of the laminate are so different under the temperatures higher than $T_{g}$.
\end{abstract}

Keywords: Carbon/epoksi, Mode I, Interlaminar fracture toughness, Effect of temperature

"Sorumlu yazar (Corresponding author): Kerimcan ÇELEBİ, kcancelebi@adanabtu.edu.tr 


\section{GíRiş}

Tabakalar arası ayrılma, delaminasyon hasarı, tabakalı kompozit malzemelerin servis ömürlerini kısıtlayan en önemli hasar türüdür [1,2]. Delaminasyon hasarının oluşumu ve malzemenin bu hasar ile kırılması, malzemeye etkiyen yüklere göre farklı biçimlerde gelişebilir. Tabakalı kompozit malzemenin maruz kaldığı yükleme türüne göre açılma modu (Mod I), kayma modu (Mod II), yırtılma modu (Mod III) veya bu kırılma modlarının bileşkeleri delaminasyon çatlağının gelişimine neden olabilir (Şekil 1). Malzemenin, tabakalar arası çatlağın başlamasına karşı göstermiş olduğu direnç ise malzeme özelliği kabul edilir ve tabakalar arası kırılma tokluğu olarak adlandırılan bu özellik, kritik şekil değiştirme enerjisi yayılım hızı $\left(G_{c}\right)$ ile ifade edilir $[3,4]$. European Structural Integrity Society (ESIS), American Society for Testing and Materials (ASTM), Japan High Polymer Center (JHPC) gibi uluslararası standart kuruluşları Mod I, Mod II ve karışık mod (Mod I\&II) yüklemeleri altında tabakalar arası kırılma tokluğunu ölçmek için test metotları oluşturmuştur [5-9]. Son yıllarda ise ESIS ve ASTM yorulma yükü altında Mod I tabakalar arası kırılma tokluğu $\left(G_{I c}\right)$ testleri için standart test metodu geliştirme çalışmaları yapmaktadır [2,10]. Tabakalar arası kırılma 1980'lerin ortasından bugüne birçok araştırmacının ilgisini çekmiş ve bu kırılma türünün mekaniği literatürde birçok açıdan irdelenmiştir.

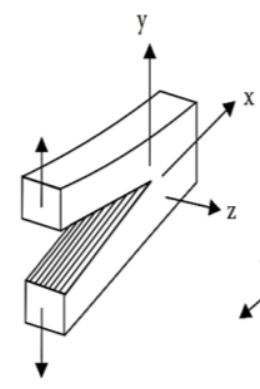

(a)

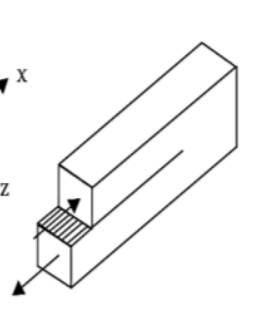

(b)

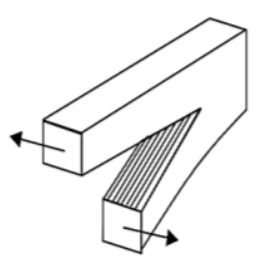

(c)
Şekil 1. Kırılma modları; (a) Mod I, ayrılma kırılması (b) Mod II, kesme kirılması (c) Mod III, yırtma kırılması [1]

\section{TABAKALAR ARASI KIRILMA ILE İLGILI ÇALIȘMALAR}

Mod I yüklemesi altında tabakalar arası kırılma testleri çift konsol kiriş numune ile yapılır. Çift konsol kiriş numuneler test öncesinde ön çatlak içerecek şekilde üretilir. Tabakalar arası kırılma matris bakımından zengin bölgelerde başlar ve çatlak ilerlerken takviye liflere yapışan matris malzeme, liflerin tiftiklenmesine neden olur. Takviye liflerden sıyrılan bu mikro lifler kırılma yüzeyleri arasında köprü oluşturur [3]. Çatlaktan hemen sonra oluşan lif köprüsü delaminasyon gelişimine karşı gösterilen direnci ve şekil değiştirme enerjisi yayılım hızını $\left(G_{\mathrm{I}}\right)$ artırmaktadır [3]. Delaminasyon çatlağı gelişirken lif köprüleri oluşmaz ise tabakalar arası kırılma tokluğu sabit bir değere sahiptir [12]. Delaminasyon çatlağını takiben lif köprüleri oluşur ise çatlak ilerledikçe $G_{I}$ değeri önce artmakta sonra sabit bir değere yaklaşmaktadır. Bu karakteristik davranış R-eğrisi davranışı olarak adlandırılır ve açılı katlı kompozit malzemelerin $0^{\circ} / 0^{\circ}$ ara yüzünde oluşan lif köprüleri tek yönlü lif takviyeli veya çapraz katlı lif takviyeli tabakalı kompozit malzemelerde oluşan lif köprülerine göre daha yoğundur [13].

Takviye lif açısının $G_{I c}$ değeri üzerine etkisini çalışan araştırmacılar, aralarında delaminasyon içeren ardışık iki tabakanın takviye lif yerleşim açısı ile çatlak ilerleme yönü arasındaki açısal fark arttıkça $G_{I c}$ değerinin arttığını belirtmişlerdir $[14,15]$. Açılı katlı tabakalı kompozit malzemelerde malzeme salt Mod I veya Mod II yüklemesine maruz kalsa da eğilme-burulma ve burulma-burulma kuvvet çiftlerinin etkisi ile çatlak ucunda hem Mod I hem de Mod II kırılması eş zamanlı olarak ortaya çıkmaktadır [16]. Açılı katlı tabakalı kompozit malzemelerde lif yerleşim açılarının neden olduğu anticlastic eğilme veya asimetrik eğilme ile çatlak ucunun çarpılmasına neden olan karış1k mod yüklemeleri nümerik metotlar ile de incelenmiştir [17-23].

Yük uygulama hızı deneysel olarak ölçülen $G_{I c}$ değerini etkileyen diğer bir faktördür. Mod I yüklemesi altındaki çift konsol kiriş numuneye 
etkiyen yük uygulama hızı arttıkça ölçülen $G_{c}$ değeri düşmektedir. Bu nedenle standart test metotlarında tavsiye edilen yük uygulama hızı değeri 1-5 mm/dak ile sınırlandırılmıştır [24-28].

Frassine ve Pavan [29] ve Frassine ve arkadaşları [30] farklı ortam sicaklıklarının $\left(-50^{\circ} \mathrm{C}, 23^{\circ} \mathrm{C}\right.$, $75^{\circ} \mathrm{C}, 130^{\circ} \mathrm{C}$ ve $170^{\circ} \mathrm{C}$ ) ve yük uygulama hızının politermid/karbon lifi ve PEEK/karbon lifi tabakalı kompozit malzemenin Mod I kırılma tokluğu üzerindeki viskoelastik etkilerini araştırmışlardır. Cowley ve Beaumont [31], tek yönlü ve çapraz katlı lif takviyeli tabakalı kompozit malzemenin yüksek sıcaklıklarda Mod I ve Mod II yükleri altında tabakalar arası kırılma tokluğunu araştırmışlardır. Araştırmacılar taramalı elektron mikroskobu ile termoset ve termoplastik matrikslerin kırılma yüzeylerini inceleyerek sıcaklığın tabakalar arası kırılma mekanizmasına etkisini açıklamaya çalışmışlardır. Kim ve arkadaşları [32] tek yönlü lif takviyeli ve açılı katlı lif takviyeli karbon lifi/epoksi tabakalı kompozit malzemelerin düşük ve yüksek sıcaklıklarda Mod I tabakalar arası kırılma tokluğu değerlerini araştırmışlardır. Yapılan çalışmalarda tek yönlü lif takviyeli tabakalı kompozit malzemenin kırılma tokluğunun hem delaminasyon başlangıcı hem de delaminasyon gelişimi için ortam sıcaklığına bağlı olmadığı ancak açılı katlı kompozit malzemenin kırılma tokluğunun ortam sicaklığına bağlı olarak değiştiği belirtilmiştir. Yukarıda özeti verilen çalışmalarda, tabakalar arası kırılma tokluğunun $\left(G_{I c}\right)$ kompozit malzemeler için malzeme özelliği olarak kabul edildiği ve bu malzeme özelliğine etki eden değişkenler hakkında birçok çalışma yapıldığ1 görülmüştür. Literatürdeki ortam sıcaklığının tabakalar arası kırılma tokluğu üzerine etkisini araştıran çalışmalar ise hem sayıca azdır hem de bu çalışmalarda ortam sıcaklığı dar bir aralıkta tutulmuştur. Tabakalı kompozit malzemeler kullanım yerlerine göre çok düşük sıcaklıklar ve yüksek sıcaklıklar altında çalışmaktadır. Tabakalı kompozit malzemeler havacılık uygulamalarında ortalama $-50^{\circ} \mathrm{C}$ ortam sıcaklığında, uzay uygulamalarında ise kriyojenik sıcaklıklarda kullanılmaktadır. Ayrıca epoksinin camsı geçiş sıcaklığı üzerinde ki sıcaklıklar sıklıkla görülmekte ve tabakalı kompozit malzemeler bu sicaklıklarda kullanılmaktadır.
Örneğin ses hızına ulaşılan uygulamalarda hava direnci ile oluşan sürtünme, malzemelerin yüzey sıcaklığını $200^{\circ} \mathrm{C}$ 'nin üzerine çıkarabilmektedir. Diğer taraftan tabakalar arası kırılma tokluğu değeri, kompozit malzeme bileşenlerinden daha çok matris malzemeye bağlı bir özelliktir. Bu çalışmada kullanılan malzeme bileşenlerinden epoksi matris malzeme, karbon lifine göre ortam sıcaklığından daha fazla etkilenmektedir. $\mathrm{Bu}$ nedenle bu çalışmada tek yönlü karbon lifi/epoksi tabakalı kompozit malzemenin Mod I tabakalar arası kırılma tokluğu ve delaminasyon gelişimi, kriyojenik ortam sıcaklıklarını ve epoksinin camsı geçiş sıcaklığ 1 üzerindeki ortam sıcaklıklarını da kapsayan geniş bir aralıkta $\left(-160^{\circ} \mathrm{C}\right.$ ile $\left.+140^{\circ} \mathrm{C}\right)$ araştırılmıştır.

\section{MATERYAL VE METOT}

$\mathrm{Bu}$ çalışmada öncelikle Çizelge 1'de özellikleri verilen $300 \mathrm{gr} / \mathrm{m}^{2}$ ağırlığa sahip tek yönlü karbon lifi kumaş ve Diglisidil Bisfenol A (DGBA) epoksi reçine kullanılarak karbon lifi/epoksi tabakalı kompozit malzemenin üretimi yapılmıştır. Üretim için vakum torbalama tekniği kullanılmıştır (Şekil 2.a). Üretilen tabakalı kompozit malzemeler 24 saat oda sıcaklığında ve sonrasında $50^{\circ} \mathrm{C}$ etüv içerisinde kurutularak malzemenin tam mukavemetini kazanması sağlanmıştır. Elde edilen levhalardan $\mathrm{CNC}$ su jeti yardımıyla numuneler kesilmiștir (Şekil 2.b). Elde edilen karbon lifi/epoksi tabakalı kompozit malzemenin mekanik özellikleri Çizelge 2'de verilmiştir.

Çizelge 1. Malzemelerin mekanik ve fiziksel özellikleri

\begin{tabular}{|c|c|c|}
\hline Malzemeler & Karbon Lif & Epoksi \\
\hline $\begin{array}{c}\text { Çekme Dayanımı } \\
(\mathrm{MPa})\end{array}$ & 4900 & $70-80$ \\
\hline $\begin{array}{c}\text { Elastisite Modulü } \\
(\mathrm{GPa})\end{array}$ & 240 & $3,2-3,5$ \\
\hline Yoğunluk $\left(\mathrm{g} / \mathrm{cm}^{3}\right)$ & 1,79 & $1,13-1,17$ \\
\hline Çap $(\mu \mathrm{m})$ & 7 & - \\
\hline
\end{tabular}



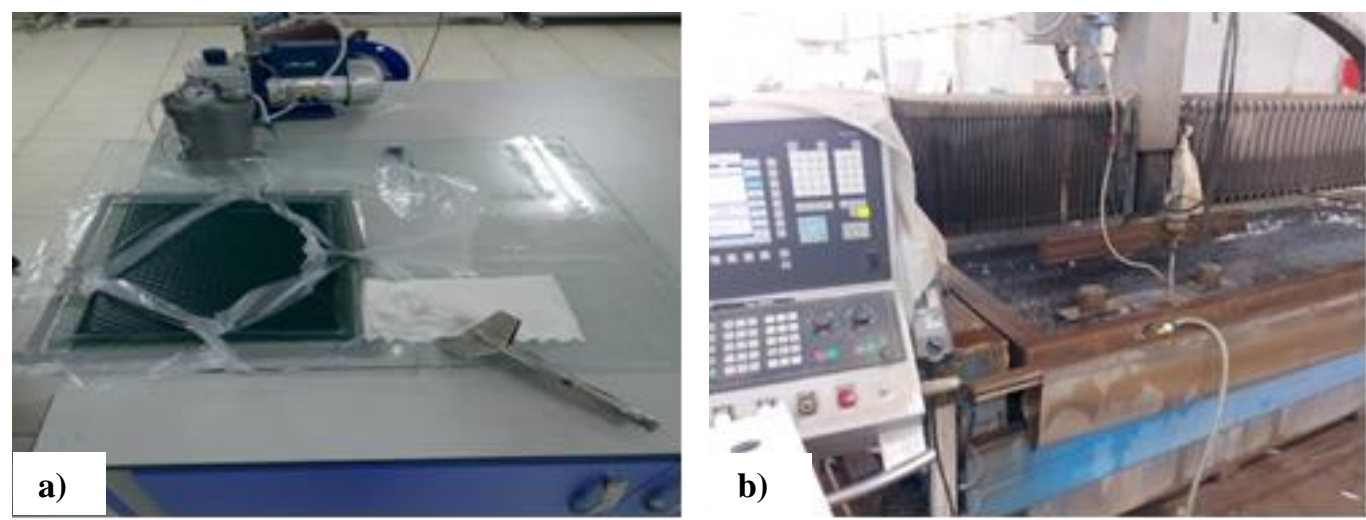

Şekil 2. Tabakalı kompozit test numunelerinin üretimi; a) Vakum torbalama tekniği, b) CNC su jeti ile numune kesimi

Çizelge 2. Karbon lifi/epoksi tabakalı kompozit malzemenin fiziksel ve mekanik özellikleri [33]

\begin{tabular}{|l|c|c|c|}
\hline \multicolumn{1}{|c|}{ Malzeme Özelliği } & Sembol & Birim & Değer \\
\hline Yoğunluk & $\rho_{C}$ & $\mathrm{~g} / \mathrm{cm}^{3}$ & 1,54 \\
\hline Hacimsel Lif Oranı & $V_{f}$ & $\%$ & 55 \\
\hline Lif Yönünde Elastik Modül & $E_{11}$ & $\mathrm{GPa}$ & 137 \\
\hline Lif Yönüne Dik Elastik Modül & $E_{22}$ & $\mathrm{GPa}$ & 10 \\
\hline Lif Yönünde Poisson Oranı & $v_{12}$ & - & 0,30 \\
\hline Lif Yönüne Dik Poisson Oranı & $v_{21}$ & - & 0,022 \\
\hline Lif Yönünde Çekme Dayanımı & $X_{t}$ & $\mathrm{MPa}$ & 1192 \\
\hline Lif Yönüne Dik Çekme Dayanımı & $Y_{t}$ & $\mathrm{MPa}$ & 21 \\
\hline Lif Yönünde Esneklik Dayanımı & $\sigma_{f}^{L}$ & $\mathrm{MPa}$ & 576,507 \\
\hline Lif Yönüne Dik Esneklik Dayanımı & $\sigma_{f}^{T}$ & $\mathrm{MPa}$ & 39,821 \\
\hline Lif Yönünde Esneklik Modülü & $E_{B}^{L}$ & $\mathrm{GPa}$ & 95,319 \\
\hline Lif Yönüne Dik Esneklik Modülü & $E_{B}^{T}$ & $\mathrm{GPa}$ & 6,539 \\
\hline Lif Yönünde Basma Dayanımı & $X_{c}$ & $\mathrm{MPa}$ & 305,28 \\
\hline Lif Yönüne Dik Basma Dayanımı & $Y_{c}$ & $\mathrm{MPa}$ & 64,7 \\
\hline Lif Yönünde Basma Modülü & $E_{11}^{c}$ & $\mathrm{MPa}$ & - \\
\hline Lif Yönüne Dik Basma Modülü & $E_{22}^{c}$ & $\mathrm{MPa}$ & - \\
\hline Kayma Dayanımı & $S_{12}$ & $\mathrm{MPa}$ & 59,45 \\
\hline Kayma Modülü & $G_{12}$ & $\mathrm{MPa}$ & 4705 \\
\hline Open hole Basma Dayanımı & $F^{\text {ohcu }}$ & $\mathrm{MPa}$ & 147 \\
\hline
\end{tabular}


E-cam lifi/epoksi malzemenin Mod I tabakalar arası kırılma özelliklerinin tespiti için yapay delaminasyon içeren ve tek yönlü karbon kumaş dizlimi $\left[0_{12}\right]$ olan çift konsol kiriş numuneler kullanılmıştır. Üretimi yapılan çift konsol kiriş numunelerin ölçüleri $(150 \times 25 \times 3,4)$, numune içerisindeki liflerin yerleşimi ve numunelerde bulunması gereken ön çatlaklar ASTM D5528-01 Test Method for Mode I Interlaminar Fracture Toughness of Unidirectional Fiber-Reinforced Polymer Matrix Composites test metoduna uygun olarak hazırlanmıştır [2]. Çift konsol kiriş numunelerin üretimi yapılırken orta ara yüze (6. Ara yüz) kalınlığı $12 \mu \mathrm{m}$ olan PET film tabakası yerleştirilmiştir. Yapay delaminasyon görevi görecek bu film tabakası, epoksi matrise yapışmaması için kalıp ayırıcı ile kaplanmıştır. Çift konsol kiriş numunesinin şematik görünümü Şekil 3'de verilmiştir. Elde edilen numuneler Shimadzu AGS-X $100 \mathrm{kN}$ üniversal test cihazı ve bu cihazın termostatik kabini kullanılarak farklı ortam sıcaklıklarında $2 \mathrm{~mm} / \mathrm{dk}$ yük uygulama hızı ile teste tabi tutulmuştur (Şekil 4). Yüksek ortam sicaklıkları termostatik kabinin elektrikli 1sitma sistemi yardımıyla, düşük ortam sıcaklıkları ise termostatik kabin içerisine sıvı azot verilerek elde edilmiştir (Şekil 5). Bu sayede $0^{\circ} \mathrm{C}, 20^{\circ} \mathrm{C}, 60^{\circ} \mathrm{C}$, $100^{\circ} \mathrm{C}, 140^{\circ} \mathrm{C}$, ile $-40^{\circ} \mathrm{C},-80^{\circ} \mathrm{C},-120^{\circ} \mathrm{C},-160^{\circ} \mathrm{C}$ ortam sıcaklıklarında testler gerçekleştirilmiştir. $160^{\circ} \mathrm{C}$ ortam sıcaklığının üzerinde ise çift konsol kiriş numuneler sertliklerini tamamen kaybettikleri ve sahip oldukları formu koruyamadıkları için gerçekleştirilememiştir.

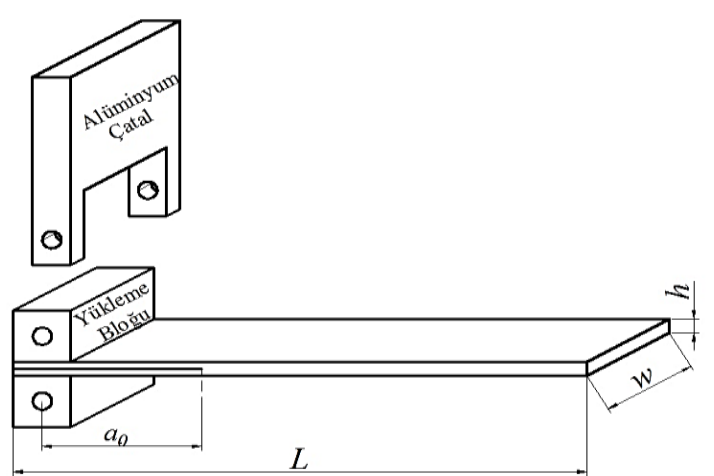

Şekil 3. Çift konsol kiriş numune

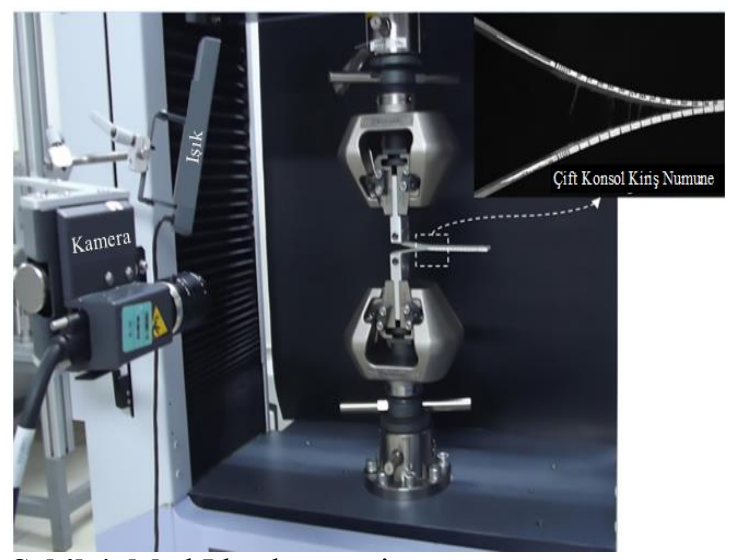

Şekil 4. Mod I kırılma testi
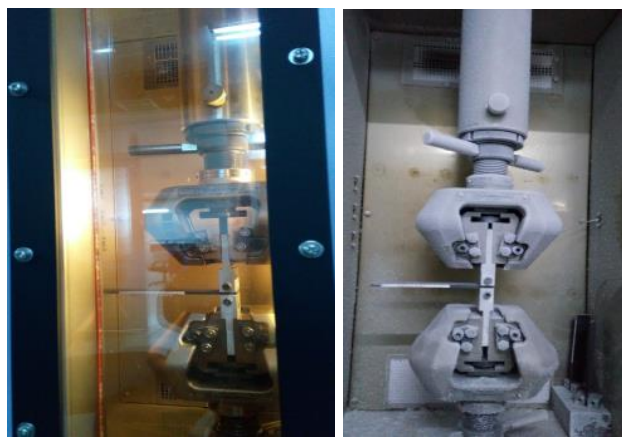

Şekil 5. Farklı ortam sıcaklıklarında yapılan mod I kırılma testleri

Kabin içerisinde ve ortam sıcaklığında yapılacak testler yüksek çözünürlüklü kamera ile 15 kat büyütülerek takip edilmiştir (Şekil 5). Bu sayede hem $G_{I c}$ değerlerini hesaplamamızı sağlayacak kritik yük $\left(P_{c r}\right)$ ve yük uygulama noktaları arası açıklık $\left(\delta_{c r}\right)$ değerleri hem de şekil değiştirme enerjisi yayılım hızını $\left(G_{I}\right)$ hesaplamamızı sağlayacak $P$ ve $\delta$ değerleri belirlenmiştir. Çatlak boyu $(a)$ da yine yüksek çözünürlüklü kamera ile takip edilmiştir. Bu sayede hem ortam sıcaklığında hem kabin içerisinde yapılan testler için hesaplamalar yapılabilmiştir. Kabin içerisinde gerçekleştirilen düşük sicaklık içerisindeki testlerde kabin camında görüşü engelleyecek buğulanma oluşmamış ve tüm testler esnasında çatlak gelişimi kolaylıkla takip edilebilmiştir. Karbon lifi epoksi kompozit malzeme için Mod I tabakalar arası kırılma tokluğu ve şekil değiştirme enerjisi yayılım hızı ASTM D 5528-01 metodunda 
belirtilen Değiştirilmiş Kiriş Teorisi (Modified Beam Theory - MBT) kullanılarak hesaplanmıştır (Eşitlik 1). Eşitlik 1'de kullanılan düzeltme faktörü (4) çift konsol kiriş numunelerin hazırlanması ve cihaza bağlanması esnasında meydana gelebilecek çarpılmaların veya burulmaların etkisini gidermek için kullanılır. $\Delta$ düzeltme faktörünün belirlenmesi ile ilgili görsel Şekil 6’da verilmiştir.

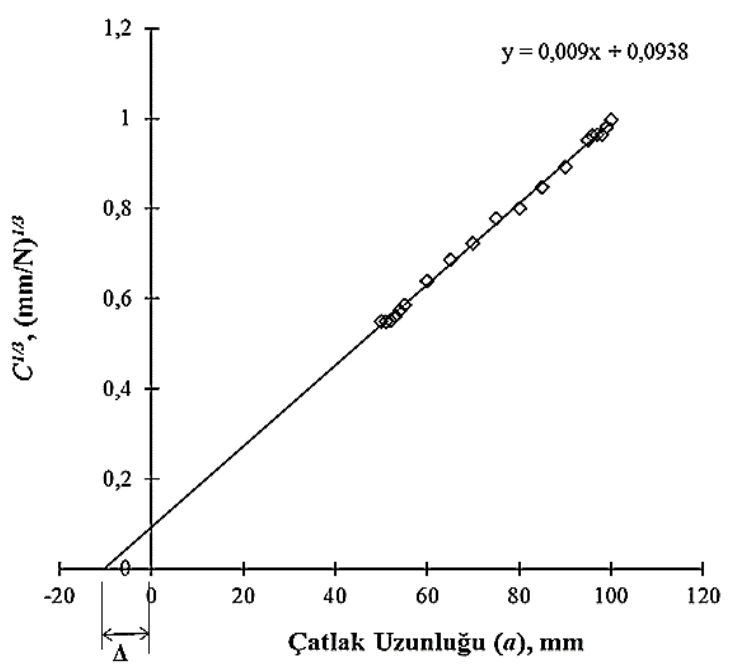

Şekil 6. Değiştirilmiş Kiriş Teorisi'ne göre düzeltme faktörünün bulunması

$G_{I}=\frac{3 P \delta}{2 w(a+|\Delta|)}$

$G_{I} \quad$ : Birim şekil değiştirme enerjisi yayılım $\mathrm{h} 1 \mathrm{zl}, \mathrm{mJ} / \mathrm{mm}^{2}$

$P \quad:$ Yük, N

$\delta \quad$ : Yük uygulama noktaları arası açıklık, $\mathrm{mm}$

$w \quad$ : Numune genişliği, mm

a : Toplam delaminasyon çatlağı uzunluğu, $\mathrm{mm}$

$\Delta \quad$ : Düzeltme faktörü

$C=\delta / P \quad:$ Kompliyans, $\mathrm{mm} / \mathrm{N}$

\section{SONUÇLAR}

Statik yük altındaki Mod I kırılma testleri $140^{\circ} \mathrm{C}$ ile $-160^{\circ} \mathrm{C}$ aralığında gerçekleştirmiştir. Test edilen karbon lifi/epoksi tabakalı kompozit malzemelere ait $P-\delta$ grafikleri Şekil 7'de gösterilmiștir. $P-\delta$ grafikleri incelendiğinde $-160^{\circ} \mathrm{C}$ ve $60^{\circ} \mathrm{C}$ aralığında delaminasyon çatlağı başlayana kadar malzemenin kompliyansının belirgin olarak değişmediği görülmüştür. Ancak $100^{\circ} \mathrm{C}$ ve $140^{\circ} \mathrm{C}$ ortam sıcaklıklarında epoksi malzemenin camsı geçiş sıcaklığı üzerine çıkıldığı ve malzeme rijitliğini kaybettiği için malzemenin kompliyansında gözle görülür değişim meydana geldiği görülmüştür. $\quad 60^{\circ} \mathrm{C}$ ortam sicaklığ malzemenin farklı davranış göstermeye başladığı kritik sıcaklık değeri olarak ortaya çıkmıştır. Kompozit malzeme üretiminde kullanılan Hexion MGS L160 epoksi reçine için camsı geçiş sıcaklığının $\quad 65^{\circ} \mathrm{C}-70^{\circ} \mathrm{C}$ aralığında olduğu düşünüldüğünde malzemenin bu ortam sıcaklıklarında mekanik davranışını değiştirmesi beklenen bir sonuçtur. Bu sicaklık değerinde malzeme tam olarak rijitliğini kaybetmemiştir ancak çift konsol kiriş numunenin kolları yüksek esneklik kazanmıştır. $\mathrm{Bu}$ sayede $\delta_{c r}$ değeri ve $P_{c r}$ değeri oldukça yükselmiş ve bu sayede tabakalar arası kırılma tokluğu da yükselmiştir. $60^{\circ} \mathrm{C}$ ortam sicaklığında tespit edilen $G_{I c}$ değeri ortam sıcaklığındaki $G_{I c}$ değerine göre $\% 58,81$ daha yüksektir. Tüm sıcaklık değerleri için karbon lifi/epoksi tabakalı kompozit malzemenin $\delta_{c r}, P_{c r}$, $G_{I c}$ ve $C$ değerleri Çizelge 3 'te verilmiştir. $100^{\circ} \mathrm{C}$ ve $140^{\circ} \mathrm{C}$ ortam sicakliklarında yapilan testlerde ise epoksi matrisin rijitliğini kaybetmesi ile çift konsol kiriş numune kolları mukavemetini kaybetmiş ve esneklikleri oldukça artmıştır. Sonuç olarak $100^{\circ} \mathrm{C}$ ve $140^{\circ} \mathrm{C}$ ortam sicakliklarinda numune kollarının yer değişimi için gerekli kuvvet değeri de düşmüş ve kompliyans değerleri artmıştır.

$60^{\circ} \mathrm{C}$ ve $100^{\circ} \mathrm{C}$ ortam sicaklığında yapılan birçok testte delaminasyon çatlağı sadece 1-5 mm aralığında ilerlemiştir. Numune kollarına kuvvet uygulanmaya devam edildiğinde ise numune üst kolu çatlak kökünden kırılmıştır (Şekil 8). Bu durum özellikle malzemenin direncini tam olarak kaybetmediği ancak yumuşamaya başladığı $60^{\circ} \mathrm{C}$ ortam sıcaklığında çokça oluşmuştur. Bu durumun yine epoksi malzemenin camsı geçiş sıcaklığı ile ilgili olduğu değerlendirilmiştir. Ayrıca $100^{\circ} \mathrm{C}$ ve $140^{\circ} \mathrm{C}$ ortam sıcaklıklarında çift konsol kiriş 
numune kollarının ayrılmaya karşı göstermiş olduğu direnç oldukça düşük iken yük uygulama noktaları arası açıklık oldukça fazladır. $100^{\circ} \mathrm{C}$ ortam sicaklığında tespit edilen $G_{I c}$ değeri ortam sıcaklığındaki $G_{I c}$ değerine göre $\% 22,140^{\circ} \mathrm{C}$ ortam sıcaklığında tespit edilen $G_{I c}$ değeri ise ortam sıcaklığındaki $G_{I c}$ değerine göre $\% 78$ daha düşüktür.

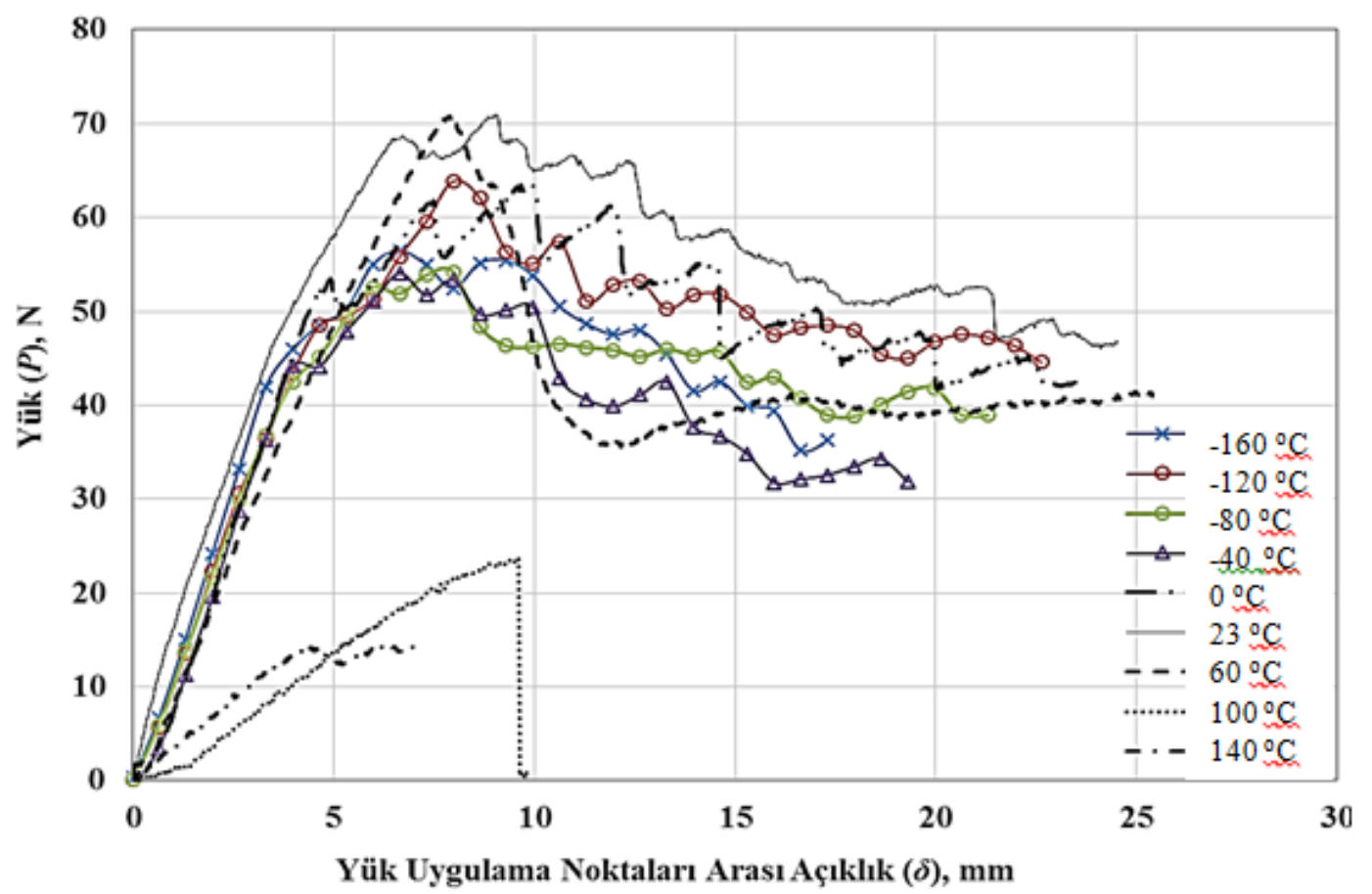

Şekil 7. Çok yüksek ve çok düşük ortam sıcaklıklarında elde edilen $P$ - $\delta$ grafikleri

Çizelge 3. Farklı ortam sıcaklıklarında elde edilen kritik değerler

\begin{tabular}{|c|c|c|c|c|}
\hline $\begin{array}{c}\text { Ortam } \\
\text { Sicaklı̆̆ } \mathbf{I} \\
\left(\mathbf{(}^{\mathbf{0}}\right)\end{array}$ & $\begin{array}{c}\boldsymbol{\delta}_{\boldsymbol{c r}} \\
(\mathbf{m m})\end{array}$ & $\boldsymbol{P}_{\boldsymbol{c r}} \mathbf{( N )}$ & $\begin{array}{c}\boldsymbol{C}, \\
(\mathbf{m m} / \mathbf{N})\end{array}$ & $\begin{array}{c}\boldsymbol{G}_{\mathbf{I} \boldsymbol{c}} \\
\left(\mathbf{m J} \mathbf{J} \mathbf{m m}^{\mathbf{2}}\right)\end{array}$ \\
\hline $\mathbf{- 1 6 0}$ & 1,7 & 20,20 & 0,08415 & 0,0368 \\
\hline $\mathbf{- 1 2 0}$ & 2,20 & 26,00 & 0,0847 & 0,0562 \\
\hline $\mathbf{- 8 0}$ & 2,31 & 26,93 & 0,0859 & 0,0632 \\
\hline $\mathbf{- 4 0}$ & 3,26 & 42,93 & 0,076 & 0,1458 \\
\hline $\mathbf{0}$ & 4,46 & 46,81 & 0,0953 & 0,2648 \\
\hline $\mathbf{2 3}$ & 4,20 & 46,62 & 0,09 & 0,2093 \\
\hline $\mathbf{6 0}$ & 7,73 & 65,60 & 0,1178 & 0,3282 \\
\hline $\mathbf{1 0 0}$ & 9,17 & 26,92 & 0,3405 & 0,1626 \\
\hline $\mathbf{1 4 0}$ & 3,87 & 11,65 & 0,332 & 0,04496 \\
\hline
\end{tabular}

Düşük ortam sıcaklıklarında $\left(0^{\circ} \mathrm{C}\right.$ ila $-160^{\circ} \mathrm{C}$ aralığı) yapılan kırılma testlerinde herhangi bir olumsuzluk görülmemiş ve numune boyunca çatlak takibi kolaylıkla yapılmıştır. Düşük ortam sicaklıklarında elde edilen $P-\delta$ grafiklerinin karakteristiği, malzemenin $23^{\circ} \mathrm{C}$ ortam sıcaklığında göstermiş olduğu $P-\delta$ karakteristiği ile oldukça benzerdir. Ancak $-80^{\circ} \mathrm{C}$ ortam sıcaklıklarından itibaren çift konsol kiriş numunenin ayrılan kollarının yer değiştirmeye karşı göstermiş olduğu reaksiyon kuvvetinde azalma görülmüş ve dolayısıyla kırılma tokluğu değerinde düşüş gözlenmiştir. Sıcaklığın düşmesi ve kriyojenik sıcaklara ulaşması ile $P_{c r}$ değerinde ve hatta $\delta_{c r}$ değerinde oluşan bu düşüş, $G_{I c}$ değerinin $23^{\circ} \mathrm{C}$ ortam sicaklığında elde edilen $G_{I c}$ değerine göre \%80'lere varan azalmaya neden olmuştur (Şekil 9). Tüm testler incelendiğinde ise karbon lifi/epoksi tabakalı kompozit malzeme 
$60^{\circ} \mathrm{C}$ ortam sicaklığında maksimum kırılma tokluğunu $\left(G_{I c}\right)$ elde etmiştir. Hatta $60^{\circ} \mathrm{C}$ ortam sıcaklığında delaminasyon çatlağı gelişmemiş çatlak kökünde oluşan gerilmeler karbon lifi/epoksi tabakalara dik yönde (intralaminar) kırılmaya neden olmuştur (Şekil 8). Delaminasyon çatlağının geliştiği ortam sıcaklıklarında ise en yüksek $G_{I c}$ değeri $0^{\circ} \mathrm{C}$ 'de elde edilmiş̧ir.

$-160^{\circ} \mathrm{C} \quad$ ila $\quad 140^{\circ} \mathrm{C}$ aralı̆̆ındaki ortam sıcaklıklarında elde edilen birim şekil değiştirme enerjisi yayılım hızlarını gösteren $\mathrm{R}$ eğrileri Sekil $10^{\prime}$ da verilmiștir. $60^{\circ} \mathrm{C}$ ve $100^{\circ} \mathrm{C}$ ortam sıcaklıklarında çatlak başlangıcından sonra çatlak ilerlemediği için R-eğrileri elde edilememiştir. $\mathrm{R}$ eğrileri incelendiğinde $23^{\circ} \mathrm{C}$ ve altındaki ortam sıcaklıklarında çatlak başlangıcından sonra $G_{I}$ değerinin arttığı görülmüştür. Sonrasında $G_{I}$ değeri sabit bir değere yaklaşmıştır. $G_{I}$ değerinin bu şekilde artması ayrılan yüzeyler arasındaki lif köprülerinin sonucudur. $23^{\circ} \mathrm{C}$ ve altındaki ortam sıcaklıklarında bu etki belirgin olarak ortaya çıkmıştır. Düşük sıcaklık değerlerinde epoksi malzemenin kırılganlığının artmasıyla çatlak gelișimi daha kararlı hale gelmis ve enerji yayılım hızı sabit değere daha çok yaklaşmıştır. $140^{\circ} \mathrm{C}$ ortam sicaklığında ise sicaklığın etkisi ile matris malzeme ile takviye lif arasındaki adhezyon ortadan kalkmış ve lif köprüleri oluşmamıştır.

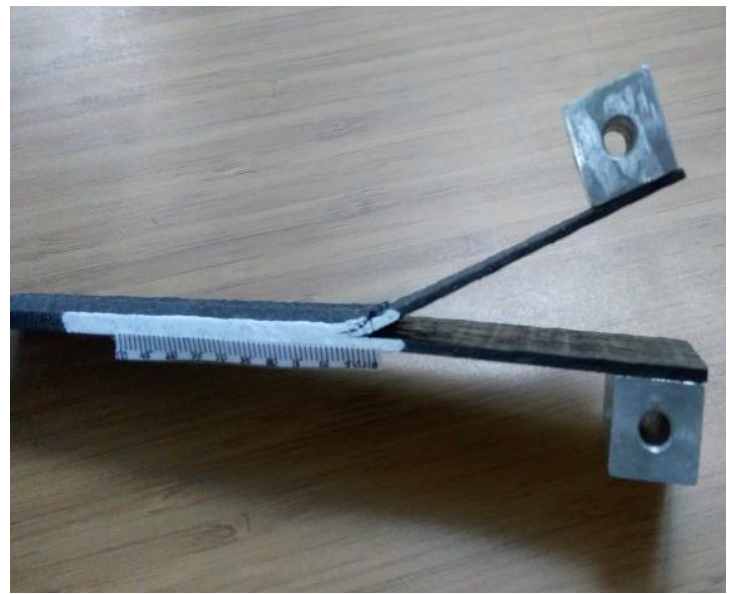

Şekil 8. $60^{\circ} \mathrm{C}$ ve üzeri ortam sıcaklıklarında çatlak kökünden kırılan numune örneği

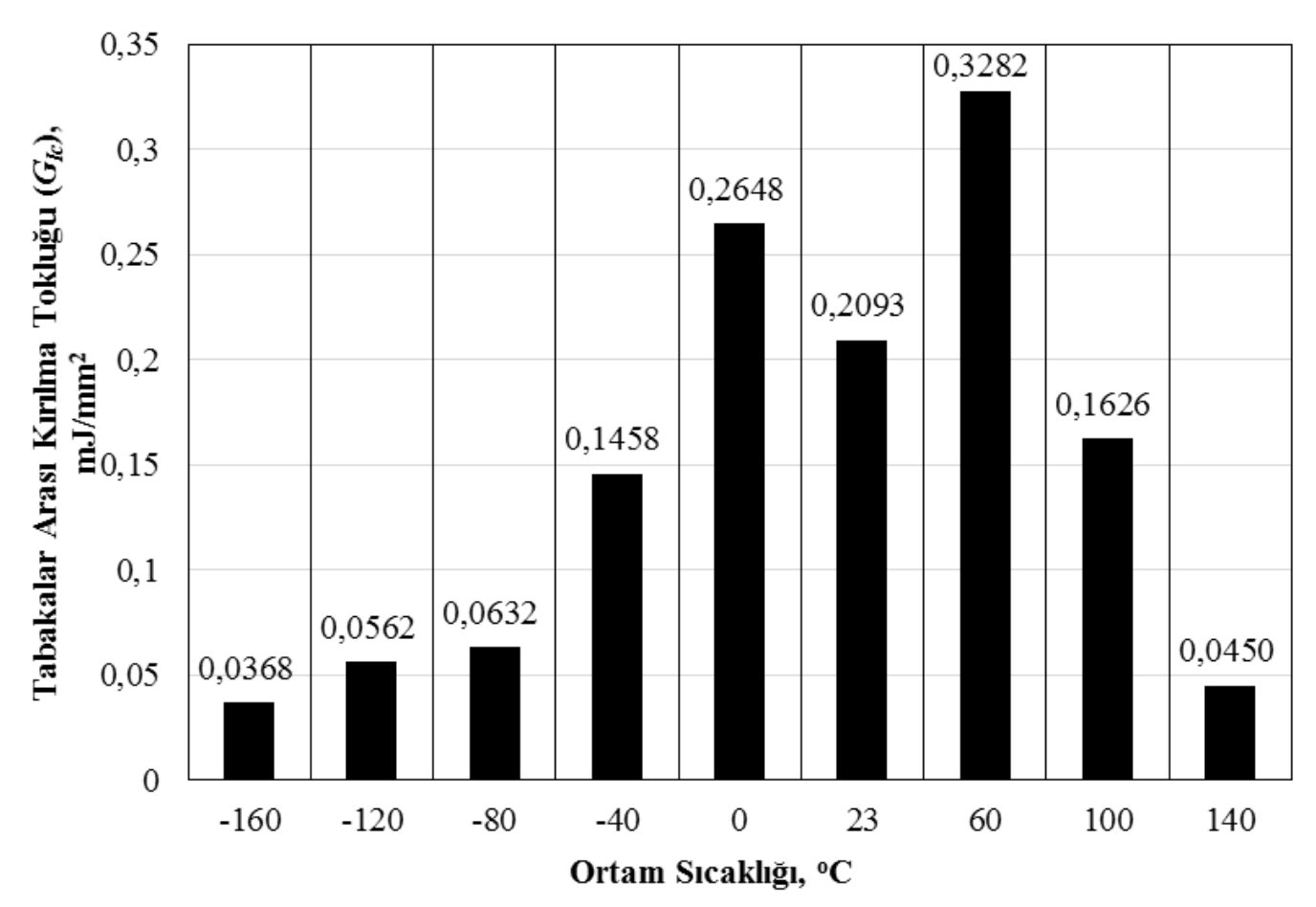

Şekil 9. Çok yüksek ve çok düşük ortam sıcaklıklarında elde edilen $G_{I c}$ grafikleri 


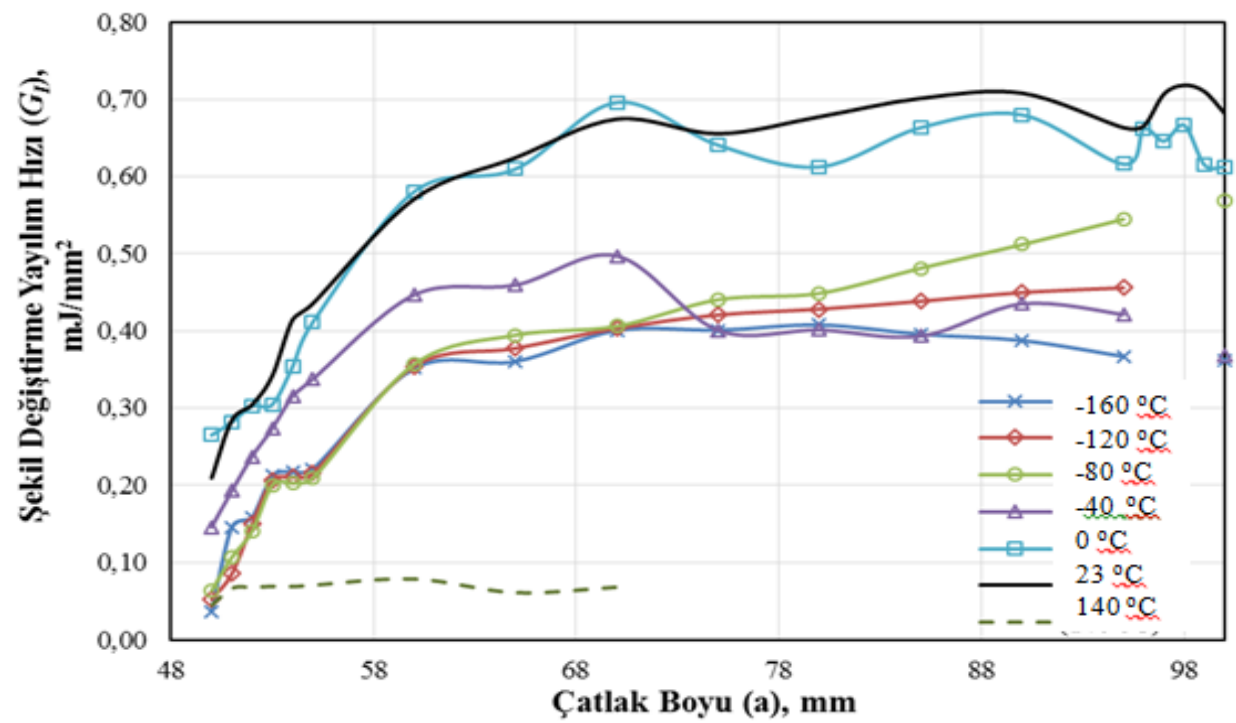

Şekil 10. Çok yüksek ve çok düşük ortam sıcaklıklarında elde edilen R-eğrileri

\section{BULGULAR}

Karbon lifi/epoksi tabakalı kompozit malzemenin çok yüksek ve çok düşük ortam sıcaklıklarındaki Mod I kırılma mekaniği üzerine yapılan bu çalışma sonucunda;

- Vakum torbalama tekniği ile üretilen karbon lifi epoksi tabakalı kompozit malzemenin statik yük altında Mod I tabakalar arası kırılma tokluğunun $\left(G_{I c}\right) 0,2093 \mathrm{~mJ} / \mathrm{mm}^{2}$ olduğu,

- Yüksek sıcaklıklarda kompozit malzeme bileşenlerinden epoksi matrisin camsı geçiş sicaklığının $\quad\left(T_{g}=65^{\circ} \mathrm{C}-70^{\circ} \mathrm{C}\right)$ bir limit oluşturduğu ve $60^{\circ} \mathrm{C}$ ortam sicaklığında malzemenin tabakalar arası kırılma tokluğunun maksimum olduğu,

- Camsı geçiş sıcaklığının üzerinde ki ortam sicakliklarında $\left(80^{\circ} \mathrm{C}, 100^{\circ} \mathrm{C}\right.$ ve $\left.140^{\circ} \mathrm{C}\right)$ ise tabakalı kompozit malzemenin rijitliğini kaybederek ayrılma yüküne direnç gösteremediği ve ortam sıcaklıği yükseldikçe kırılma tokluğunun düștüğü,

- $\quad 0^{\circ} \mathrm{C}$ ortam sıcaklığındaki $G_{I c}$ değerinin $23^{\circ} \mathrm{C}^{\prime} \mathrm{de}$ tespit edilen $G_{I c}$ değerinden yüksek olduğu,
- Ortam sıcaklığı düştükçe ve kriyojenik sıcaklık değerlerine yaklaştıkça tabakalı kompozit malzemenin kırılganlığının $\operatorname{arttığı~ve~} G_{I_{c}}$ değerinin düştüğü,

- Orta sıcaklığının kriyojenik sıcaklık değerlerine yaklaşması ile çatlak gelişiminin daha kararlı hale geldiği, bulgularına ulaşılmıştır.

Sonuç olarak vakum torbalama tekniği ile üretilen tek yönlü lif takviyeli karbon lifi/epoksi tabakalı kompozit malzemenin, Mod I tabakalar aras1 kırılma tokluğu $\left(G_{I c}\right)$ malzemenin bulunduğu ortam sıcaklığına son derece bağlıdır. Bu sonuç farklı ortam sicaklıklarındaki tabakalar arası kırılma tokluğunun, karbon lifinin mekanik özelliklerinden ziyade kompozit malzeme bileşenlerinden matris malzemenin termo-mekanik özelliklerine bağlı olduğunu göstermektedir.

\section{TEŞEKKÜR}

Yazarlar bu çalışmaya finansal destek sağlayan Adana Bilim ve Teknoloji Üniversitesi Araştırma Projeleri Birimine (Proje No: 16103006) teşekkür eder. 


\section{KAYNAKLAR}

1. Argüelles, A., Vina, J., Canteli, A. F., Castrillo, M. A., Bonhomme, J., 2008. Interlaminar Crack Initiation and Growth Rate in a CarbonFibre Epoxy Composite under Mode-I Fatigue Loading. Composites Science and Technology, $68,2325-2331$

2. Brunner, A. J., Murphy, N., Pinter, G., 2009. Development of a Standardized Procedure for the Characterization of Interlaminar Delamination Propagation in Advanced Composites under Fatigue Mode I Loading Conditions. Engineering Fracture Mechanics(76), 2678-2689.

3. O'Brien, T. K., 1998. Interlaminar Fracture Toughness: The Long and Winding Road to Standardization. Composites Part B, 29(1), 57-62.

4. Kenane, M., Azari, Z., Benmedakhene, S., Benzeggagh, M. L., 2011. Experimental Development of Fatigue Delamination Threshold Criterion. Composites Part B: Engineering, 42, 367-375.

5. Hojo, M., Kageyama, K., Tanaka, K., 1995. Prestandardization Study on Mode I Interlaminar Fracture Toughness Test for CFRP in Japan. Composites, 26, 243-255.

6. Davies, P., Blackman, B. K., Brunner, A. J., 1998. Standard Test Methods for Delamination Resistance of Composite Materials: Current Status. Applied Composite Materials, (5), 345-364.

7. JIS Standard K 7086, Testing Methods for Interlaminar Fracture Toughness of Carbon Fiber Reinforced Plastics, 1993.

8. ISO International Standard 15024, Fiberreinforced Plastic Composites - Determination of Mode I Interlaminar Fracture Toughness, Gic, Unidirectionally Reinforced Materials, 2001.

9. ASTM D5528-13, 2013. Standard Test Method for Mode I Interlaminar Fractre Toughness of Unidirectional Continuous Fiber Reinforced Polymer Matrix Composites.

10. Stelzer, S., Brunner, A. J., Argüelles, A., Murphy, N., Pinter, G., 2012. Mode I Delamination Fatigue Crack Growth in
Unidirectional Fiber Reinforced Composites: Development of a Standardized Test Procedure. Composites Science and Technology (72), 1102-1107.

11. Carlsson, L. A., Adams, D. F., Pipes, R. B., 2014. Experimental Characterization of Advanced Composite Materials. Boca Raton: CRC Press.

12. de Moura, M. S., Campilho, R. S., Amaro, A. M., Reis, P. B., 2010. Interlaminar and Intralaminar Fracture Characterization of Composites Under Mode I Loading. Composite Structures, 92, 144-149.

13. Shokrieh, M. M., Heidari-Rarani, M., 2011. Effect of Stacking Sequence on R-curve Behavior of Glass/Epoxy DCB Laminates with 0o//0o Crack Interface. Materials Science and Engineering A, 529, 265-269.

14. Chou, I., 1998. Effect of Fiber Orientation and Moisture Absorption on the Interlaminar Fracture Toughness of CFRP Laminates. 7(4), 377-394. Advanced Composite Materials.

15. Shetty, M. R., Vijay Kumar, K. R., Sudhir, S., Raghu, P., Madhuranath, A. D., Rao, R. M., 2000. Effect of Fibre Orientation on Mode-I Interlaminar Fracture Toughness of Glass Epoxy Composites. 19(8), 606-620.

16. Mathews, M. J., Swanson, S. R., 2007. Characterization of the Interlaminar Fracture Toughness of a Laminated Carbon/Epoxy Composite. Composites Science and Technology (67), 1489-1498.

17. Davidson, B. D., Krüger, R., König, M., 1996. Effect of Stacking Sequence on Energy Release Rate Distributions in Multidirectional DCB and ENF Specimens. Engineering Fracture Mechanics, 55(4), 557-569.

18. de Morais, A. B., de Moura, M. F., Marques, A. T., de Castro, P. T., 2002. Mode-I Interlaminar Fracture of Carbon/Epoxy Crossply Composites. Composites Science and Technology, 62 (5), 679-686.

19. de Morais, A. B., 2004. Analysis of Mode II Interlaminar Fracture of Multidirectional Laminates. (35), 51-57. Composites: Part A.

20. Pereira, A. B., de Morais, A. B., 2004. Mode I Interlaminar Fracture of Carbon/epoxy Multidirectional Laminates. Composites Science and Technology, 64, 2261-2270. 
21. Pereira, A. M., 2004. Mode II Interlaminar Fracture of Glass/epoxy Multidirectional Laminates. (35), 265-272. Composites: Part A.

22. Prombut, P., Michel, L., Lachaud, F., Barrau, J. J., 2006. Delamination of Multidirectional Composite Laminates at 0/Ply Interfaces. Engineering Fracture Mechanics, 73(16), 2427-2442.

23. Sebaey, T. A., Blanco, N., Lopes, C. S., Costa, J., 2011. Numerical Investigation to Prevent Crack Jumping in Double Cantilever Beam Tests of Multidirectional Composite Laminates. Composites Science and Technology, 71(13), 1587-1592.

24. Smiley, A. J., Pipes, R. B., 1987. Rate Effects on Mode I Interlaminar Fracture Toughness in Composite Materials. Journal of Composite Materials, 21(7), 670-687.

25. Mall, S., Law, G. E., Katouzian, M., 1987. Loading Rate Effect on Interlaminar Fracture Toughness of a Thermoplastic Composite. Journal of Composite Materials, 21(6), 569-579.

26. Kusaka, T., Hojo, M., Mai, Y.-W., Kurokawa, T., Nojima, T., Ochiai, S., 1998. Rate Dependence of Mode I Fracture Behaviour in Carbon-Fibre/Epoxy Composite Laminates. Composites Science and Technology (58), 591-602.

27. Hug, G., Thevenet, P., Fitoussi, J., Baptiste, D., 2006. Effect of Loading Rate on Mode I Interlaminar Fracture Toughness of Laminated Composites. Engineering Fracture Mechanics (73), 2456-2462.

28. Zabala, H., Aretxabaleta, L., Castillo, G., Aurrokoetxea, J., 2015. Loading Rate Dependency on Mode I Interlaminar Fracture Toughness of Unidirectional and Woven Carbon Fibre Epoxy Composites. Composite Structures, 121, 75-82.

29. Frassine, R., Pavan, A., 1995. Viscoelastic Effects on the Interlaminar Fracture Behaviour of Thermoplastic Matrix Composites: I. Rate and Temperature Dependence in Unidirectional PEI/Carbon-Fibre Laminates. Composites Science and Technology, 54, 193-200.

30. Frassine, R., Rink, M., Pavan, A., 1996. Viscoelastic Effects on the Interlaminar Fracture Behaviour of Thermoplastic Matrix
Composites: II. Rate and Temperature Dependence in Unidirectional PEEK/CarbonFibre Laminates. Composites Science and Technology, 1253-1260.

31. Cowley, K. D., Beaumont, P. W., 1997. The Interlaminar and Intralaminar Fracture Toughness of Carbon-Fibre/polymer Composites: The Effect of Temperature. Composite Science and Technology, 57, 1433-1444.

32. Kim, H. S., Wang, W.-X., Takao, Y., 1999. Effects of Temperature and Fiber Orientation on the Mode I Interlaminar Fracture Toughness of Carbon/epoxy Composites. ICCM12 Conference, s. 276-288. Paris.

33. Özarslan, H., Yavuz, H., Darıcık, F., 2016. Elektrikli Araç Uygulamaları için Kompozit Malzeme ile Hafif Şase Tasarımı ve Geliştirilmesi. International Conference on Material Science and Technology in Cappadocia (IMSTEC'16), s. 699-703. Nevşehir. 
